\title{
Association of the Carrot Pathogen Alternaria dauci With New Diseases, Alternaria Leaf Speck, of Lettuce and Celery in California
}

Steven T. Koike, Richard F. Smith, and Michael D. Cahn, University of California Cooperative Extension, Salinas 93901; and Barry M. Pryor, School of Plant Sciences, University of Arizona, Tucson 85721

Accepted for publication 24 May 2017.

\begin{abstract}
In 2014 an unidentified disease was found on lettuce and celery grown in the Salinas Valley, Monterey Co., CA. Lettuce leaf symptoms were round to oval spots, 2 to $4 \mathrm{~mm}$ in diameter, white to tan, with a brown border. Celery leaf spots were round to oval, 2 to $4 \mathrm{~mm}$ in diameter, white to tan, with a chlorotic border. Initially it was thought that the damage was caused by chemical drift; however, field personnel noted the association of the disease with nearby carrots infected with Alternaria leaf blight. Microscopic examination of lettuce and celery leaves showed obclavate, brown, multicelled conidia in the spot centers, and a fungus was consistently isolated from this tissue. Cultural, morphological, and

molecular analyses confirmed the fungus to be Alternaria dauci. Isolates of $A$. dauci from lettuce, celery, and carrot were pathogenic on all three crops. Field surveys showed that disease severity was greatest on the side of the lettuce or celery field closest to carrots. This is the first documentation that the carrot pathogen $A$. dauci can cause a disease on lettuce and celery grown in the field. The disease is designated as Alternaria leaf speck. Alternaria dauci was consistently isolated from nearby spinach plants showing identical symptoms and signs. However, pathogenicity tests were inconsistent and additional studies are needed to document A. dauci on spinach.
\end{abstract}

In 2014, a new, widespread disease developed on California lettuce (Lactuca sativa L.) and celery (Apium graveolens L. var. dulce (Miller) Pers.) grown in coastal Monterey County's Salinas Valley. Initial symptoms on lettuce consisted of small (approximately $1 \mathrm{~mm}$ in diameter), water-soaked leaf spots that were round, oval, or irregularly shaped with curved edges. As the disease developed, the spots expanded to 2 to $4 \mathrm{~mm}$ in diameter, turned mostly tan to light brown, and were observed from both adaxial and abaxial leaf surfaces (Fig. 1). Spots often developed dark brown borders with the inner tissue sunken and sometimes cracked. Small (1 to $2 \mathrm{~mm}$ in diameter), tan, elliptical to elongated spots also developed on lettuce leaf midribs. Such spots were found on iceberg, romaine, green leaf, red leaf, and oak leaf types. On celery, initial symptoms were small (approximately $1 \mathrm{~mm}$ in diameter), water-soaked leaf spots that were round, oval, or irregularly shaped with curved edges. The spots expanded to 2 to $4 \mathrm{~mm}$ in diameter, were tan to white, and were observed from both adaxial and abaxial leaf surfaces (Fig. 1). Spots had chlorotic borders and the inner tissues were not sunken or cracked. Small (1 to $2 \mathrm{~mm}$ in diameter), tan, irregularly shaped spots also developed on celery petioles. Leaf spots on both lettuce and celery generally did not coalesce into each other, and because of their small size and large numbers, growers referred to them as "specks." These symptoms did not match any known lettuce or celery diseases documented in California. In addition to lettuce and celery, a single field of spinach (Spinacia oleracea L.) exhibited similar symptoms.

The loss of product quality was significant. The single spinach field was the most severely affected because of the zero tolerance for any defects on leaves. Lettuce was the second most affected because hundreds of specks formed on leaves, forcing harvesters to

Corresponding author: Steven T. Koike; E-mail: stkoike@ucdavis.edu

(C) 2017 The American Phytopathological Society trim off more leaves than usual and resulting in reduced head size and weight. For celery, hundreds of specks formed per leaflet; even though most celery foliage is trimmed off at harvest, some leaves are retained on the top end of the petiole. The remaining celery leaves and petioles having the speck symptoms reduced the quality of the harvested product. In 2014, over 20 lettuce and celery plantings were confirmed as having these speck symptoms. Because these symptoms resemble burn from agrichemicals, field personnel and university extension agents initially believed the specks could be caused by chemical drift or overspray with herbicides or other pesticides.

However, some farmers and pest control advisors (PCAs) noted that symptoms on lettuce, celery, and spinach apparently were not associated with pesticide applications and that affected fields were in close proximity to carrots (Daucus carota L. subsp. sativum (Hoffm.) Arcang.) that were severely diseased with Alternaria leaf blight caused by Alternaria dauci (Kuhn) Groves \& Skolko. Many of the affected lettuce and celery fields were downwind of diseased carrots. The objectives of this study were the following: to identify the cause of these new lettuce and celery symptoms and complete Koch's postulates for the recovered, suspected pathogen; establish the relationship between the lettuce and celery diseases; and suggest management options for growers.

\section{Isolation of a Fungus and its Association With Leaf Specks}

Leaf samples were collected from one spinach, five celery, and five lettuce fields affected with the speck symptom. Ten leaves per sample were examined with a dissecting microscope (magnification 7.3 to $120 \times$ ). For all leaves of all crops, approximately 70 to $85 \%$ of the specks contained one or more conidia in or near the centers of the specks (Fig. 2). When examined with a compound microscope, conidia were brown, multicelled, obclavate with an apical beak, and shriveled. Based on these morphological features, the shriveled 
conidia from lettuce, celery, and spinach specks appeared to be those of an Alternaria species. Conidia were not borne on conidiophores but were lying prone on the leaf, as if deposited and stuck to the surface. For the lettuce specks with cracked epidermis, mycelial threads could be seen spanning the gap between cracked edges. No other fungal structures or active sporulation were present.

Records of lettuce and celery fields exhibiting the speck symptoms were compiled. All such fields were located south of the

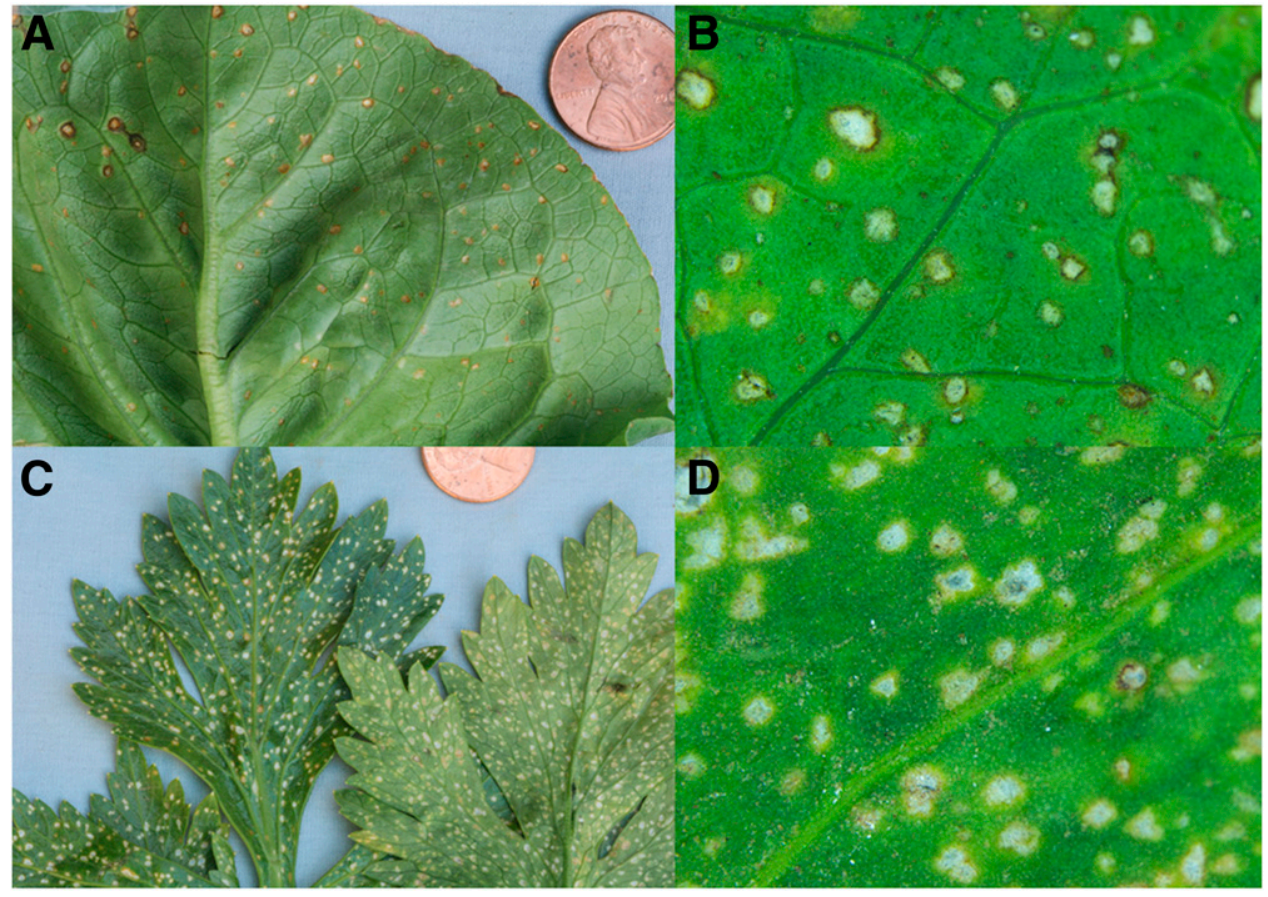

FIGURE 1

Leaf specks caused by Alternaria dauci on field-grown lettuce ( $\mathbf{A}$ and $\mathbf{B}$ ) and celery (C and $\mathbf{D})$.

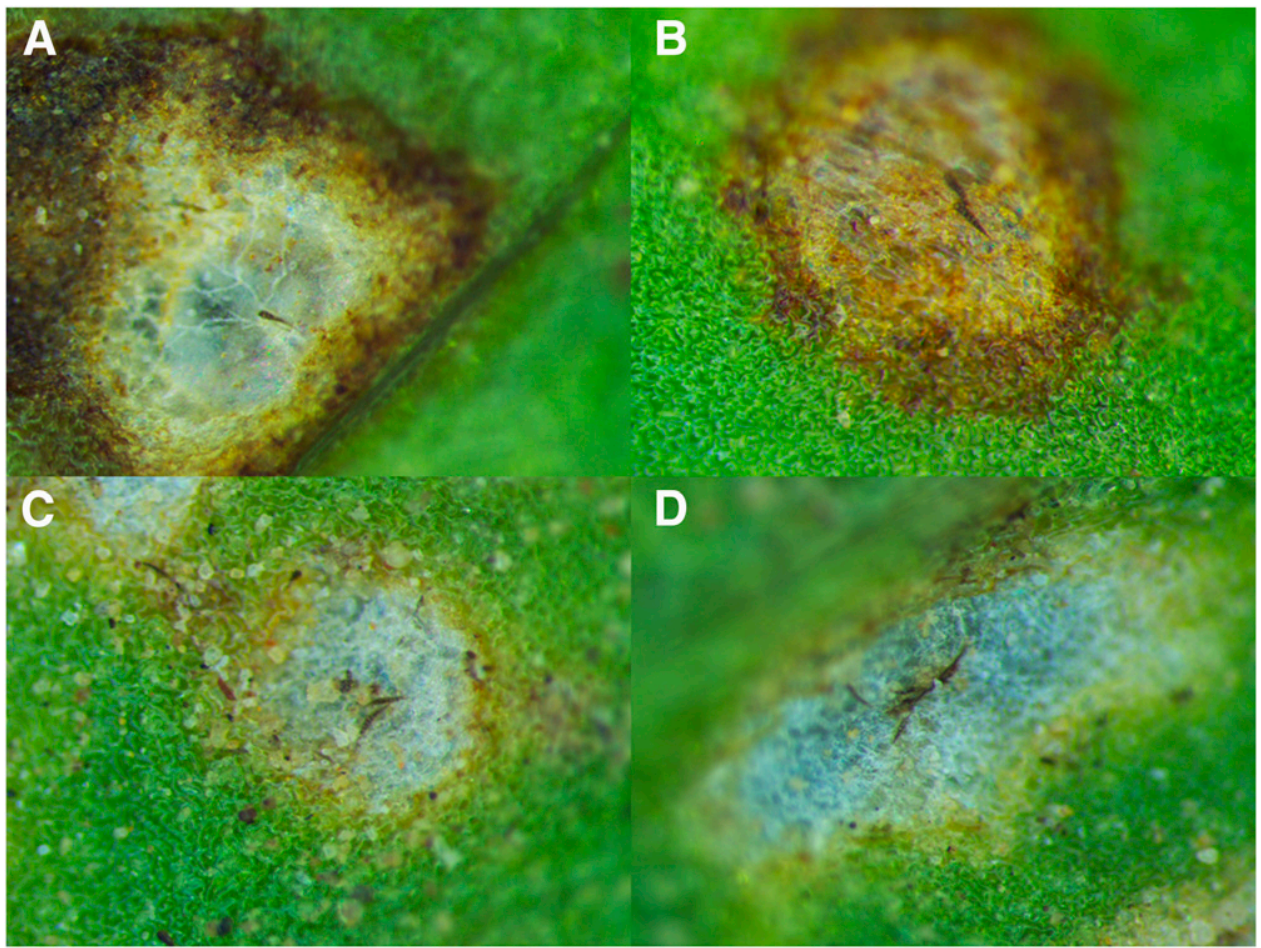

FIGURE 2

Leaf specks on field-grown lettuce (A and B) and celery (C and D) with Alternaria dauci conidia deposited in the center of the specks (viewed with a dissecting microscope at 120x). 
Soledad region $\left(36.427620^{\circ} \mathrm{N} ; 121.324171^{\circ} \mathrm{W}\right)$ in the Salinas Valley and were either next to or in close proximity of a carrot field infected with A. dauci. In the Salinas Valley, most of the carrot crop is planted south of Soledad. Therefore, these geographical records provided a preliminary indication of an association between speck cases and diseased carrots.

To isolate a possible causal agent, symptomatic leaves from lettuce ( 9 fields), celery ( 8 fields), spinach (1 field), and carrot (7 fields) were collected from Salinas Valley ranches. Symptomatic sections of leaves were excised for ease of handling. These leaf pieces were surface disinfested in $0.1 \%$ sodium hypochlorite for 1 min, then rinsed in sterile distilled water three times. Tissue was removed from the outer margins of the specks, placed into Petri plates containing acidified ( $2 \mathrm{ml} \mathrm{85 \%} \mathrm{lactic} \mathrm{acid/liter)} \mathrm{corn} \mathrm{meal}$ agar (Sigma-Aldrich, St. Louis, MO), and plates incubated at $22^{\circ} \mathrm{C}$. After 3 to 5 days, gray to olive-green mycelium grew out from excised tissue pieces; reproductive propagules were not observed. Hyphal tips from the edges of the colonies were transferred to V8juice agar and incubated at $22^{\circ} \mathrm{C}$ under fluorescent lights ( $12 \mathrm{~h} /$ day). After 7 days, all colonies produced abundant conidia that were produced mostly solitary and obclavate, bearing a major, long filamentous beak; these isolates therefore appeared to be $A$. dauci (Simmons 2007). Representative isolates were obtained from single spores and stored for further study. To explore the possibility that the coastal $A$. dauci pathogen could be a specialized variant able to infect lettuce and celery, carrot leaves with symptoms of Alternaria leaf blight were obtained from the central valley Lamont/Bakersfield area (Kern Co., CA), where carrot acreage is extensive but lettuce crops are limited and celery is not grown commercially. Alternaria dauci recovered during isolations from this sample was also maintained as isolates obtained from single spores.

\section{Identification and Characterization of the Fungal Agent}

Morphological characteristics of the colony and conidia were determined for 20 isolates each from lettuce, celery, and carrot. For spinach, 10 isolates were studied. For colony morphology, isolates were transferred to Petri plates containing potato dextrose agar (PDA; Sigma-Aldrich, St. Louis, MO). Plates were incubated at $22^{\circ} \mathrm{C}$ in darkness for 10 days. After incubation, cultures were examined for colony color, margin, texture, and development of pigments or crystals in the agar medium. To characterize the sporulation habit, isolates were transferred to Petri plates containing $0.05 \times$ standard PDA ("weak PDA" [WPDA]) and were incubated for 7 days in a lighted incubator (12-h photoperiod) (Hong and Pryor 2004). After incubation, using prepared slides and a compound microscope (400 to $1000 \times$ ) with substage illumination, 20 conidia were randomly selected from each isolate and were examined for length and width of conidium body, number of transverse septa, length of apical beak, and branching of apical beak, if present. The colony and conidium characteristics of a reference isolate of $A$. dauci from carrot from California (CBS 117097) and Florida (ATCC 36614) were also determined and compared with those of the coastal lettuce, celery, spinach, and carrot isolates. Using JMP Statistical Discovery Software v10.0 (SAS Institute Inc., Cary, NC), an analysis of variance (ANOVA) was conducted on the morphometric data to determine if there were significant statistical differences between the isolates.

On PDA, all isolates collected from Salinas Valley lettuce, celery, spinach, and carrot produced light-gray colonies that were surrounded by a violet-colored, diffusible pigment in the agar medium. Colonies were wooly in texture with even margins, and few conidia were produced on this medium. On WPDA, conidia of all coastal isolates were brown, obclavate, with 2 to 10 transverse septa and
0 to 2 longitudinal septa per conidium segment (Fig. 3). Conidia all had a characteristic single, hyaline to pale brown, long apical beak. Conidial measurement means of lettuce, celery, spinach, and carrot isolates from the Salinas Valley ranged from 19.2 to $24.0 \mu \mathrm{m}$ wide and 73.0 to $93.0 \mu \mathrm{m}$ long (Table 1). Beak lengths ranged from 136.8 to $214.4 \mu \mathrm{m}$ (Table 1 ). A low percentage of these beaks was bifurcated. ANOVA results indicated that the three conidial measurements (width, length, beak length) of the coastal lettuce, celery, spinach, and carrot isolates were not statistically different from each other or from the Florida and Kern Co. carrot reference isolates ( $P=0.65,0.14$, and 0.22 , respectively) (Table 1$)$. These cultural and morphological features are consistent with descriptions of A. dauci of carrot (Groves and Skolko 1944; Simmons 2007).

For DNA analysis, the protein coding gene gpd was sequenced and compared with sequences of known isolates of $A$. dauci and other Alternaria species in section Porri (Lawrence et al. 2012). DNA extraction and purification were conducted according to previously described protocols (Pryor and Gilbertson 2000). PCR amplification of target locus was performed using primers gpd1/ gpd2 (Berbee et al. 1999), in a PCR mixture that contained $10 \mathrm{mM}$ of each primer, $200 \mathrm{mM}$ dNTP, $2.5 \mu \mathrm{l} 10 \times$ Taq reaction buffer, 2 units of AmpliTaq-DNA polymerase, $2.5 \mathrm{mM} \mathrm{MgCl}_{2}$, and $10 \mathrm{ng}$ template DNA in a final reaction volume of $25 \mu \mathrm{l}$. DNA sequences of PCR-amplified fragments were determined with an ABI PRISM 377 DNA sequencer using BigDye Terminator chemistry (PerkinElmer/ABI, Foster City, CA). The sequences of both strands of each fragment were determined for sequence confirmation. The sequences of two isolates each from coastal lettuce, celery, spinach, and carrot were determined and compared with sequences from the A. dauci reference isolates from carrot in Florida (ATCC 36613) and Kern County (San Joaquin Valley, CA) (BMP 0156) (Table 1), and other Alternaria spp. obtained from GenBank. Sequences were aligned with MacVector. In some cases, manual adjustments of sequence alignments were performed using the data editor program of MacClade Phylogenetic Software (version 3.05; Sinauer Associates, Sunderland, MA). Phylogenetic analyses were performed using programs contained in PAUP Phylogenetic Software (version 4.0-beta; Sinauer Associates, Inc., Sunderland, MA). Phylogenetic trees were constructed using maximum parsimony. For parsimony analysis, heuristic searches for the most parsimonious trees were conducted using random step-wise addition of 1000 replicates and branch swapping by tree bisection-reconnection. Sequence gaps were recoded and treated as a fifth character. For statistical analyses of resolved trees, 1000 nonparametric bootstrap replicates were performed under the MP criteria.

In the molecular analysis, a 580-bp fragment was amplified from each isolate. Multiple sequence alignments revealed $100 \%$ identity among all recovered isolates (Table 1). Comparisons with other published gpd sequences of $A$. dauci revealed 99 to $100 \%$ identity, confirming that all coastal lettuce, celery, spinach, and carrot isolates are $A$. dauci. Sequence alignments were identical between coastal $A$. dauci isolates and the $A$. dauci reference isolate from California (CBS 117097), which is used as a representative isolate for taxonomic purposes (Simmons 2007); alignments were 99.8\% identical between these same coastal isolates and the reference isolate from Florida (ATCC 36613) (Table 1). Sequence alignment comparisons among the coastal isolates and 10 additional $\mathrm{A}$. dauci gpd GenBank accessions revealed 98.5 to $100 \%$ identity.

\section{Pathogenicity of Alternaria dauci Isolates}

To test pathogenicity of the various $A$. dauci isolates, four replicate sets of plants ( 6 plants per set per cultivar) were prepared and 
consisted of romaine lettuce (cultivar Sun Valley, 5 weeks old), celery (cv. Conquistador, 8 weeks old), and carrot (cv. Maverick, 6 weeks old). Representative A. dauci isolated from lettuce (5 isolates), celery ( 2 from celery leaves, 1 from a celery petiole), coastal carrot (1), and Kern County carrot (1) (Table 2) were each tested individually. Isolates were grown in Petri plates containing V8-juice agar that were incubated at $22^{\circ} \mathrm{C}$ under fluorescent lights $(12 \mathrm{~h} /$ day $)$. After 2 weeks, conidial suspensions were prepared in water, adjusted
A

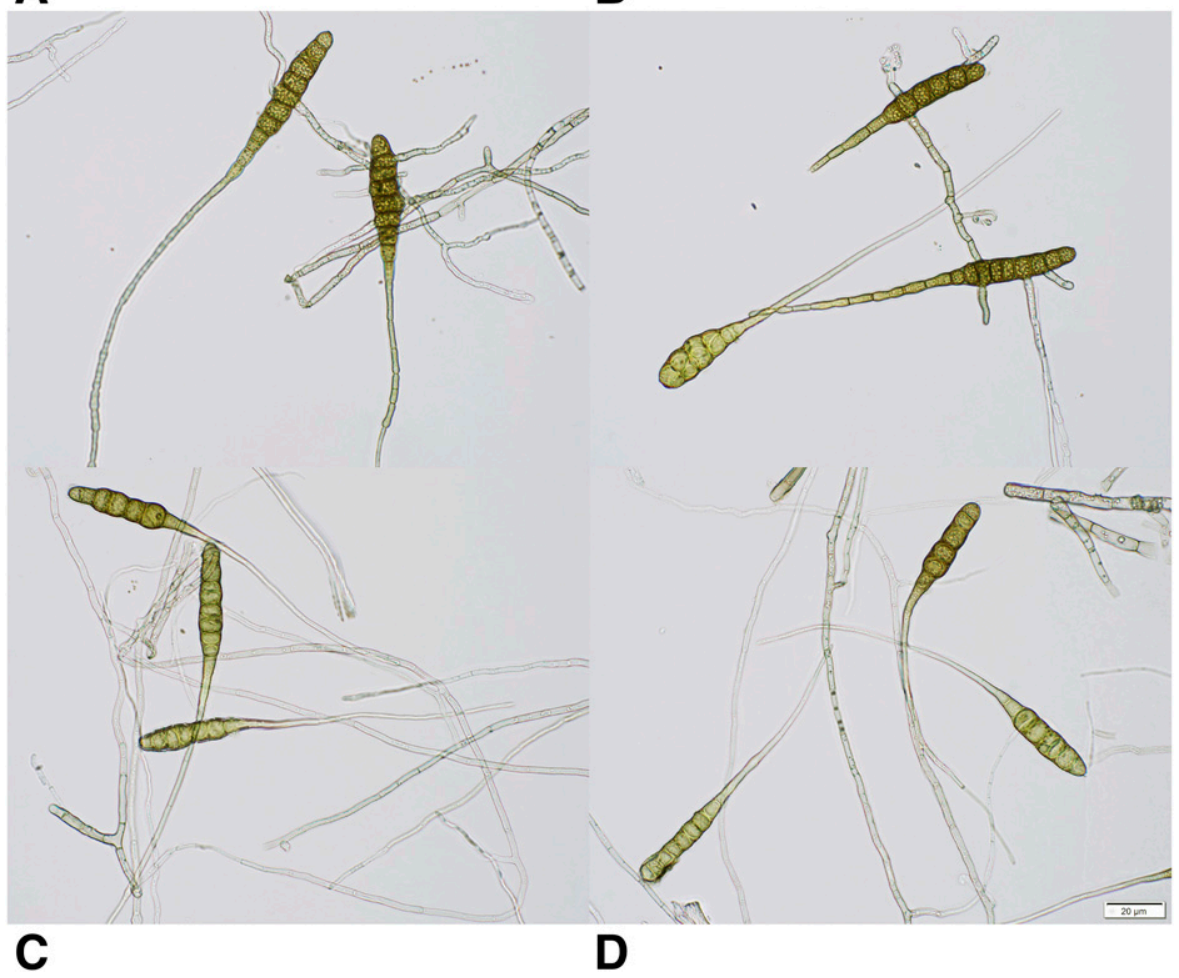

\section{FIGURE 3}

Conidia of Alternaria dauci isolates from Salinas Valley carrot (A and B) and lettuce (C and $\mathbf{D})$. Cultures were grown for 7 days on WPDA medium and incubated at $22^{\circ} \mathrm{C}$ under 12-h photoperiod. Magnification was at 400x. Final photos were obtained by stacking multiple images using Helicon Focus version 6.7 .1 Pro.

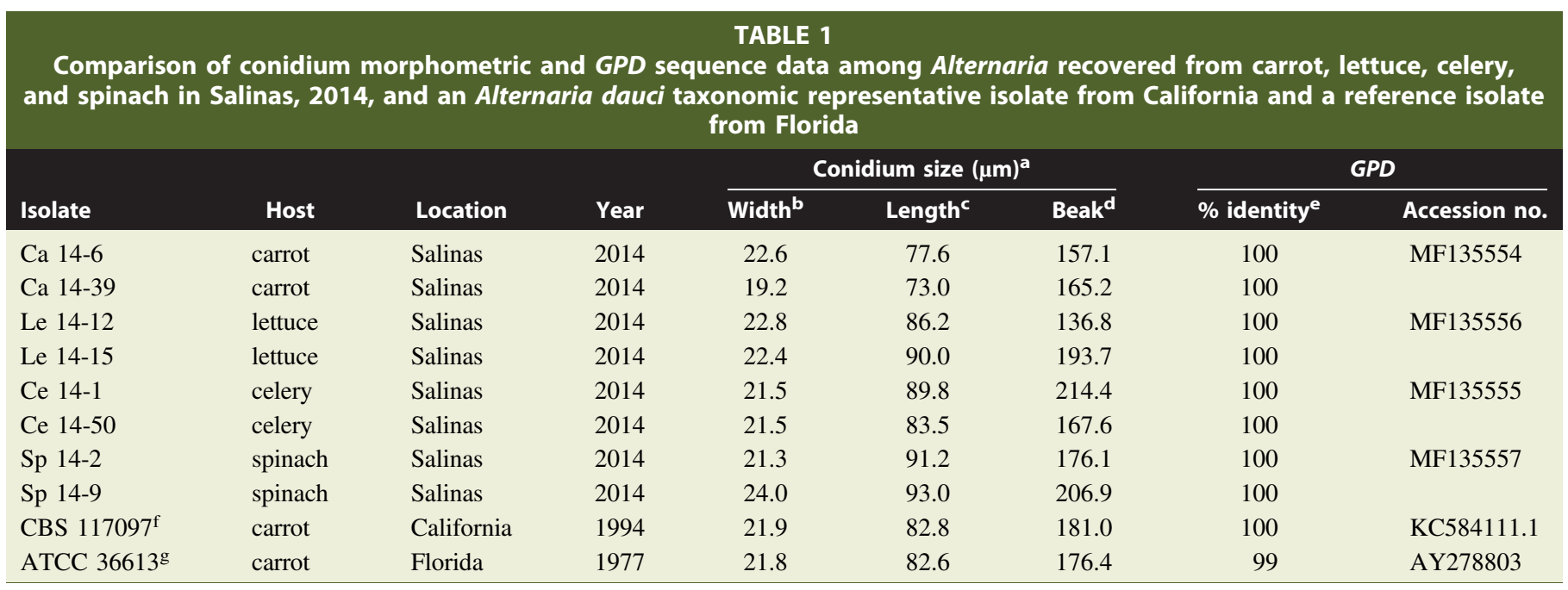

${ }^{a}$ Values are the means of 20 conidia.

${ }^{\mathrm{b}}$ Values within column are not significantly different $(P=0.65)$.

${ }^{c}$ Values within column are not significantly different $(P=0.14)$.

${ }^{\mathrm{d}}$ Values within column are not significantly different $(P=0.22)$.

e Comparison with CBS 110971.

${ }^{\mathrm{f}}$ Representative isolate of Alternaria dauci (EGS 46-006).

${ }^{\mathrm{g}}$ Reference isolate of Alternaria dauci. 
to $1 \times 10^{4}$ conidia/ml using a hemacytometer, and sprayed onto test plants until runoff. Inoculated plants were incubated for $24 \mathrm{~h}$ under high-humidity conditions by placing the plants inside plastic bags. Plants were subsequently arranged on a greenhouse bench in a randomized complete block design and maintained at 24 to $26^{\circ} \mathrm{C}$ day, 20 to $22^{\circ} \mathrm{C}$ night. Control sets of plants were sprayed with water and treated in the same way as the inoculated sets.

Three days after inoculation, carrot plants inoculated with all lettuce, celery, and carrot isolates of $A$. dauci showed water-soaked, angular lesions. Inoculated lettuce and celery plants initially showed leaf specks after 8 and 12 days, respectively, for all isolates. After 21 days, the one leaf per cultivar per replication that exhibited the most severe symptoms was selected and evaluated using the following disease severity scale: $1=$ no leaf specks or lesions; $2=<10$ specks or lesions per leaf; $3=>10$ but $<25$ specks or lesions per leaf; $4=>25$ specks or lesions per leaf or coalescing of lesions and blight symptoms. Using Statgraphics Centurion XVI (Warrenton, VA) software, an ANOVA was conducted on the disease severity means to determine if there were significant statistical differences between the isolates inoculated onto each plant host. For means that showed statistically significant differences $(P=0.05)$, the Fisher's least significant difference (LSD) procedure was used.

In the first experiment, carrot plants consistently showed the most severe lesion development when inoculated with any isolate from lettuce, celery, or carrot; these severe symptoms were all ranked as category 4 using the severity scale; lesions eventually coalesced and resulted in blight-like symptoms (Table 2). Inoculated lettuce developed disease from all isolates and disease severity values ranged from 2.3 to 3.0 (Table 2). Lettuce isolate Le 14-06 was the only isolate that had a significantly lower disease severity value (2.3) at

\begin{tabular}{|c|c|c|c|c|c|c|}
\hline \multicolumn{7}{|c|}{$\begin{array}{c}\text { TABLE } 2 \\
\text { Disease severity of Alternaria dauci isolates inoculated onto } \\
\text { lettuce, celery, and carrot }\end{array}$} \\
\hline \multirow[b]{2}{*}{ Isolate $^{a}$} & \multicolumn{3}{|c|}{$\begin{array}{l}\text { Disease severity: } \\
\text { experiment } 1^{b}\end{array}$} & \multicolumn{3}{|c|}{$\begin{array}{l}\text { Disease severity: } \\
\text { experiment } 2^{\mathbf{b}}\end{array}$} \\
\hline & Lettuce & Celery & Carrot & Lettuce & Celery & Carrot \\
\hline Le $14-01$ & 3.0 & 1.8 & 4.0 & 2.5 & 1.5 & 4.0 \\
\hline Le $14-06$ & 2.3 & 1.5 & 4.0 & 2.5 & 2.0 & 4.0 \\
\hline Le $14-12$ & 2.8 & 2.0 & 4.0 & 3.0 & 2.0 & 4.0 \\
\hline Le $14-25$ & 3.0 & 1.8 & 4.0 & 3.0 & 2.3 & 4.0 \\
\hline Le $14-43$ & 2.8 & 1.8 & 4.0 & 2.8 & 2.0 & 4.0 \\
\hline Ce 14-01 & 3.0 & 2.0 & 4.0 & 3.3 & 1.8 & 4.0 \\
\hline Ce 14-09 & 2.5 & 2.0 & 4.0 & 3.0 & 2.0 & 4.0 \\
\hline Ce 14-50pet & 3.0 & 1.8 & 4.0 & 3.0 & 2.3 & 4.0 \\
\hline Ca $14-01$ & 3.0 & 2.0 & 4.0 & 3.3 & 2.3 & 4.0 \\
\hline Ca 14-Kern & 2.5 & 1.8 & 4.0 & 3.0 & 2.0 & 4.0 \\
\hline $\operatorname{LSD}(P=0.05)^{\mathrm{c}}$ & 0.53 & N.S. ${ }^{d}$ & N.S. & N.S. & N.S. & N.S. \\
\hline Water control ${ }^{\mathrm{e}}$ & 1.0 & 1.0 & 1.0 & 1.0 & 1.0 & 1.0 \\
\hline
\end{tabular}

${ }^{\mathrm{a}} \mathrm{Le}=$ lettuce isolate $\mathrm{Ce}=$ celery isolate $\mathrm{Ca}=$ carrot isolate; $\mathrm{pet}=$ isolate obtained from celery petiole; Kern = isolate obtained from carrot grown in Kern County.

${ }^{\mathrm{b}}$ Disease severity was rated using the following scale: $1=$ no leaf specks or lesions; $2=<10$ specks or lesions per leaf; $3=>10$ but $<25$ specks or lesions per leaf; $4=>25$ specks or lesions per leaf or coalescing of lesions and blight symptoms.

${ }^{c}$ If analysis of variance (ANOVA) indicated statistically significant differences at $P=0.05$, the Fisher's least significant difference (LSD) procedure was used to discriminate between means.

${ }^{\mathrm{d}}$ N.S. = not statistically significant.

${ }^{\mathrm{e}}$ The water control means were not included in the ANOVA calculations.
$P=0.05$. Inoculated celery also developed leaf specks but disease severity was lower than that for lettuce; severity values ranged from 1.5 to 2.0 , and mean severity values for the various isolates were not statistically different at $P=0.05$ (Table 2). Control lettuce, celery, and carrot plants developed no leaf specks, lesions, or any disease symptoms; these disease severity values $($ all $=1)$ were not included in the ANOVA. From all inoculated lettuce, celery, and carrot leaves, a fungus morphologically identical to $A$. dauci was reisolated from the symptoms; subsequent molecular analysis confirmed the isolates to be $A$. dauci.

This pathogenicity experiment was repeated and results were similar (Table 2). All isolates caused severe lesion development and blight on carrot (all severity values $=4$ ). On lettuce, the isolates causing disease had means ranging from 2.5 to 3.3; these means were not statistically different from each other at $P=0.05$ (Table 2). Inoculated celery had speck severity ranging from 1.5 to 2.3 ; again, severity values for the various isolates were not significantly different (Table 2). A. dauci was reisolated from leaf specks and lesions for all cultivars. These two inoculation tests therefore fulfill Koch's postulates and conclusively demonstrate that $A$. dauci is the causal agent of these diseases of lettuce and celery.

The methods described above were also used to test the ability of the spinach isolates of $A$. dauci to infect spinach. Inoculation experiments were conducted three times. However, no specks developed on inoculated spinach in the first two experiments, and only a few specks were observed in the third.

\section{Disease Severity Relative to Carrot Fields}

Numerous anecdotal observations led to the hypothesis that lettuce and celery disease severity was greatest on the side of the field adjacent to carrots with severe Alternaria leaf blight. To test this hypothesis, in 2014 three lettuce (Let1, Let2, Let3) and two celery (Cell, Cel2) fields were evaluated for disease severity in relation to distance from an upwind carrot field with severe Alternaria leaf blight. Within each lettuce and celery field, three locations relative to the adjacent carrots were selected: $1=$ fewer than $15 \mathrm{~m}$ inside the field edge adjacent to the carrot field; $2=$ the midpoint of the field; $3=$ fewer than $15 \mathrm{~m}$ inside the field edge furthest away from the carrot field. The distance (meters) of locations 1, 2, and 3 from the carrots was measured at each field site. For each of the three sample locations, four replicate samples of symptomatic leaves were collected randomly, with each sample consisting of five leaves. For each leaf, the number of specks in two $4-\mathrm{cm}^{2}$ areas was determined using a dissecting microscope in the laboratory. Data were converted to number of specks $/ \mathrm{cm}^{2}$ and mean values were compared using an ANOVA (PROC GLM) in SAS 9.3. Because each examined field was planted to only one crop (either lettuce or celery), separate ANOVA analyses were conducted to evaluate differences in specks between crop types and among fields. The first analysis evaluated the main effects of crop type, location, and the interaction of crop type and location. The second ANOVA evaluated effects of field, location, and the interaction of field and location.

In the first ANOVA, the mean number of specks was statistically different $(P=0.001)$ between crop types and locations in the fields (Table 3), with the highest number of specks observed on celery and at the location closest to the carrots (Fig. 4). The interaction between crop type and location was not statistically significant $(P>0.158)$ (Table 3). The second ANOVA revealed significant differences among fields $(P=0.0001)$ and also among locations within fields $(P=0.0001)$ (Table 4$)$, with the highest number of specks in field Cel2 and at the location closest to the carrots (Fig. 4). In addition, the interaction of field and location was significant $(P=0.0005)$ (Table 4), presumably because field Let 3 did not have significantly different levels of specks among collection locations. 
The disease severity data of the four fields (Let1, Let2, Cell, Cel2) which had significantly different levels of specks at the collection locations were analyzed by regression using PROC REG in SAS to model the relationship between distance from the carrot fields and disease severity. The speck data were normalized to

\begin{tabular}{|c|c|c|c|c|}
\hline \multicolumn{5}{|c|}{$\begin{array}{c}\text { TABLE } 3 \\
\text { Analysis of variance of speck data comparing disease } \\
\text { severity between lettuce and celery }\end{array}$} \\
\hline Source & $\begin{array}{l}\text { Degrees } \\
\text { of freedom }\end{array}$ & $\begin{array}{c}\text { Mean } \\
\text { square }\end{array}$ & F-value & $P$ value \\
\hline Croptype & 1 & 5686.24 & $146.34^{\mathrm{a}}$ & 0.0012 \\
\hline Croptype (replicate) & 3 & 38.86 & 0.55 & 0.6516 \\
\hline Location $^{\mathrm{b}}$ & 2 & 606.86 & 8.57 & 0.0007 \\
\hline Croptype $\times$ location & 2 & 135.61 & 1.91 & 0.1586 \\
\hline
\end{tabular}

${ }^{\text {a }} \mathrm{F}$-value was calculated using croptype (replicate) for the mean square error term.

${ }^{\mathrm{b}}$ Location $=$ place in the lettuce or celery field relative (near side, middle, far side) to an adjacent carrot field and from which samples were collected to assess disease severity.

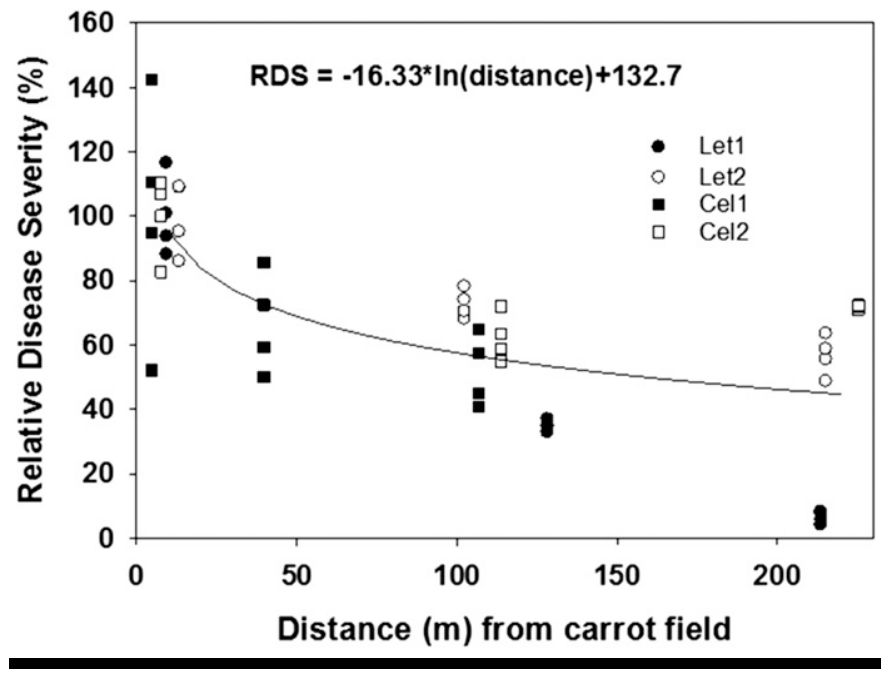

FIGURE 4

Relative disease severity (RDS) of Alternaria leaf speck in two lettuce (Let1, Let2) and two celery (Cel1, Cel2) fields planted adjacent to carrots infected with Alternaria dauci. $P<0.0001 ; \mathrm{R}^{2}=0.55$.

\begin{tabular}{lcrrr}
\multicolumn{5}{c}{ TABLE 4} \\
\multicolumn{4}{c}{ Analysis of variance of speck data comparing disease } \\
& $\begin{array}{l}\text { severity among fields } \\
\text { Degrees } \\
\text { of freedom }\end{array}$ & $\begin{array}{c}\text { Mean } \\
\text { square }\end{array}$ & F-value & P value \\
Source & 4 & 2047.85 & $60.41^{\mathrm{a}}$ & $<0.0001$ \\
Field & 12 & 33.90 & 2.72 & 0.0129 \\
Field (replicate) & 2 & 606.86 & 48.70 & $<0.0001$ \\
Location $^{\mathrm{b}}$ & 8 & 62.87 & 5.05 & 0.0005 \\
\hline Field $\times$ location & 8 &
\end{tabular}

${ }^{\text {a }} \mathrm{F}$-value was calculated using field (replicate) for the mean square error term.

${ }^{\mathrm{b}}$ Location $=$ place in the lettuce or celery field relative (near side, middle, far side) to an adjacent carrot field and from which samples were collected to assess disease severity. relative disease severity (RDS) by dividing the number of specks for each sample by the average number of specks at location 1 (location closest to the carrot fields): RDS $=$ Specks $* 100 /$ AvgSpecks $_{\text {loc } 1}$, where Specks is the number of specks observed per square $\mathrm{cm}$, and AvgSpecks $_{\text {loc1 }}$ is the average number of specks for samples collected at location 1 .

The regression analysis showed a highly significant $(P<0.0001$, $\left.\mathrm{R}^{2}=0.55\right)$ logarithmic relationship between RDS and the distance from the carrot fields (Fig. 4). Because RDS was normalized for the level of specks observed adjacent to the carrot fields, the regression model was not significantly improved $(P>0.10)$ by including separate intercepts for crop type (lettuce and celery). Average RDS decreased by greater than $50 \%$ at a distance further than $150 \mathrm{~m}$ from the carrot fields (Fig. 4).

\section{Importance and Management}

This is the first documentation that $A$. dauci is a pathogen of lettuce and celery that are grown under commercial field conditions. Cultural, morphological, and molecular analyses confirmed that the isolates obtained from coastal field-grown lettuce, celery, spinach, and carrot all were A. dauci. Repeated pathogenicity experiments using multiple isolates from lettuce, celery, and carrot demonstrated that each isolate was pathogenic on all three of these crops. The inoculation experiments also showed that under greenhouse conditions all $A$. dauci isolates were extremely virulent on carrot but less aggressive on lettuce and celery. Based on the nature of the symptoms on both lettuce and celery, we propose that these new diseases be named Alternaria leaf speck of lettuce and Alternaria leaf speck of celery. Because the spinach pathogenicity tests were inconsistent, additional studies would be needed to document that $A$. dauci is pathogenic to spinach. Such studies could involve changing the incubation conditions of the inoculated plants or using different spinach cultivars. It is curious, however, that in the field the leaf specks on spinach had the same appearance and presence of conidia as found with lettuce and celery, and that $A$. dauci was consistently isolated from such specks on spinach leaves, but pathogenicity could not be confirmed.

We have speculated on the reasons behind these new diseases on lettuce and celery. One possibility would be the development of a coastal $A$. dauci strain or variant that, due to the proximity of extensive lettuce and celery acreages, developed the ability to infect these other crops. However, because an isolate of $A$. dauci from carrots grown in Kern County, where commercial lettuce is limited ( $<130 \mathrm{ha})$ and celery is not grown, had identical morphological, molecular, and pathogenic profiles, it seems unlikely that the coastal outbreaks of disease on lettuce and celery were due to such variants. Rather, these outbreaks are more likely due to the unusually severe occurrence of Alternaria leaf blight on coastal carrots in 2014. In this season, the majority of the Monterey County carrot acreage was infected with $A$. dauci; numerous fields were so severely affected that disease incidence was $100 \%$ and 50 to $75 \%$ of the foliage in these fields was completely dead by August. These carrot fields therefore served as sources of extremely high levels of inoculum that rained upon nearby, downwind lettuce and celery plantings. In 2015, disease caused by $A$. dauci again occurred on some of these same ranches planted to carrot, lettuce, and celery. However, disease severity on carrot was much lower in this season and the number of reported diseased lettuce and celery fields was correspondingly low.

Based on published reports that thoroughly characterized the pathogen and demonstrated pathogenicity, it appears that $A$. dauci in the field is primarily a carrot pathogen (Farrar et al. 2004; Koike et al. 2007). While Koch's postulates and isolate characterization have not been completed in all cases, $A$. dauci is reported to infect 
a number of other plants, such as celery and wild species, in the Apiaceae family (Farr and Rossman 2016; Neergaard 1977; Netzer and Kenneth 1969; Soteros 1979). In addition to our verification that $A$. dauci can infect field-grown celery in California, celery has been reported elsewhere as a host, though most of these reports are presented in the form of host-pathogen lists that do not include any characterization or pathogenicity documentation (David 1988; Ginns 1986; Neergaard 1957; Richardson 1990; Strandberg 1992).

Well-documented reports of $A$. dauci causing disease on fieldgrown non-Apiaceae crops are rare. Neergaard (1945) conducted host range studies on seedlings of non-Apiaceae hosts in test tubes and reported moderate virulence on lettuce. However, Neergaard pointed out that such tests are highly artificial and may not provide evidence for pathogenesis in the field. Other reports list lettuce as a host but did not characterize the pathogen or conduct pathogenicity studies (Joly 1964; Richardson 1990). A number of other non-Apiaceae crops are recorded as hosts, though such reports are mostly in the form of records in a host-pathogen list (Farr and Rossman 2016). Boedo et al. (2012) conducted greenhouse inoculation studies and showed that two isolates of $A$. dauci caused weak reactions (most foliar disease ratings were 1 or 2 on a scale of 0 to 9 ) when inoculated onto corn salad (Valerianella olitora), cress (Nasturtium officinale), radish (Raphanus sativus), and tomato (Solanum lycopersicum). However, the authors did not find these diseases occurring on crops in the field. Our report is therefore the first confirmation that $A$. dauci can cause disease on lettuce grown in the field and is the first documentation of any Alternaria disease occurring on lettuce grown in California.

To manage Alternaria leaf speck of lettuce and celery, several components of an integrated pest management (IPM) strategy should be employed within the context of carrot production. Site selection is of primary importance. A. dauci conidia are readily dispersed by winds (Langenberg et al. 1977), so growers should avoid planting lettuce and celery downwind from and close to carrot plantings and instead plant nonhost crops in these locations. Our field surveys showed that lettuce and celery planted downwind from and close to infected carrots suffered severe disease, and that there was a decreasing disease severity gradient associated with increasing distance from the infected carrot field for most locations. Since $A$. dauci can survive on carrot residues for one year (Pryor et al. 2002), crop rotation schemes should also avoid putting lettuce and celery into fields previously occupied by severely diseased carrots, though evidence is lacking that lettuce and celery can become infected by soilborne inoculum of this pathogen.

Fungicides should also provide protection for lettuce and celery. In a 2015 field experiment that we completed in the Salinas Valley, replicated plots of lettuce were treated twice with one of seven fungicides. The crop was subsequently inoculated with an $\mathrm{A}$. dauci isolate from carrot. At the end of the experiment, all fungicides resulted in disease levels that were significantly lower than untreated control, and these included azoxystrobin (Quadris, Syngenta, Greensboro, NC), boscalid (Endura, BASF, Research Triangle Park, NC), chlorothalonil (Bravo Weather Stik, Syngenta), cyprodinil + fludioxonil (Switch, Syngenta), iprodione (Rovral, Bayer, Research Triangle Park, NC), mancozeb (Dithane F45, Dow AgroSciences, Indianapolis, IN), and penthiopyrad (Fontelis, DuPont, Wilmington, DE) (unpublished data). With the exception of chlorothalonil (which is used for Alternaria leaf blight control for carrot), all of these fungicides are already registered for lettuce in California.

The IPM strategies for controlling Alternaria leaf speck on lettuce and celery include the management of $A$. dauci on carrot. Disease on carrot can be controlled by using pathogen-free seed, rotating so as not to plant carrot in fields containing infested carrot residues (a two-year rotation away from carrots is usually recommended), selecting sites that are not close to or upwind of lettuce and celery, and applying fungicides such as chlorothalonil (Pryor et al. 2002; Rogers and Stevenson 2010). The planting of pathogen-free seed is of particular importance because all carrot fields in the Salinas Valley are irrigated with overhead sprinklers, which allows for the development of Alternaria leaf blight when infested seed is used (Ben-Noon et al. 2003).

Finally, this unexpected development of severe Alternaria leaf speck disease, caused by the carrot pathogen $A$. dauci, on lettuce and celery provides an excellent reminder of the need to carefully and thoroughly conduct plant disease diagnostics. Following the initial outbreak of symptoms, some industry personnel and university researchers attributed the symptoms to an unknown abiotic factor. However, the astute observations of other growers and PCAs encouraged researchers to re-examine the case. Once the brown, beaked, Alternaria-like spores were observed in the center of all those specks, a more careful diagnostic and investigative process ensued.

\section{Acknowledgments}

We acknowledge the California Leafy Greens Research Board and Mary Zischke for supporting this project. We thank the following growers and pest control advisors: Kyle Alpers, Pete Anecito, Gary Beck, Tim Benedix, Marvin Borzini, Wyatt Duncan, Kris Headley, Cecilio Mendoza, Charles Nieto, Mike McCord, and Kevin Vaughan. We thank the following for assistance with the study: Patty Ayala, Sharon Benzen, Gerard Denny, Keita Goto, John Guerard, Kat Kammeijer, Stacy Mauzey, Rob Pybas, Gustavo Reyes, Bree Rodriquez, and Alexandra Wollenman. We thank Tom Turini for pre-submission review of the manuscript. Steven Koike dedicates this paper to the late Arthur H. McCain.

\section{Literature Cited}

Ben-Noon, E., Shtienberg, D., Shlevin, E., and Dinoor, A. 2003. Joint action of disease control measures: A case study of Alternaria leaf blight of carrot. Phytopathology 93:1320-1328.

Berbee, M. L., Pirseyedi, M., and Hubbard, S. 1999. Cochliobolus phylogenetics and the origin of known, highly virulent pathogens, inferred from ITS and glyceraldehyde-3-phosphate dehydrogenase gene sequences. Mycologia 91: 964-977.

Boedo, C., Benichou, S., Berruyer, R., Bersihand, S., Dongo, A., Simoneau, P., Lecomte, M., Briard, M., Le Clerc, V., and Poupard, P. 2012. Evaluating aggressiveness and host range of Alternaria dauci in a controlled environment. Plant Pathol. 61:63-75.

David, J. C. 1988. Alternaria dauci. CMI Descriptions of pathogenic fungi and bacteria No. 951. Mycopathologia 103:105-124.

Farr, D. F., and Rossman, A. Y. 2016. Fungal Databases. Syst. Mycol. Microbiol. Lab., USDA-ARS, Washington, DC. https://nt.ars-grin.gov/fungaldatabases/ Retrieved January 29, 2016

Farrar, J. J., Pryor, B. A., and Davis, R. M. 2004. Alternaria diseases of carrot. Plant Dis. 88:776-784.

Ginns, J. H. 1986. Compendium of Plant Disease and Decay Fungi in Canada, 1960-1980. Publ. 1813. Research Branch, Agriculture Canada, Ottawa.

Groves, J. W., and Skolko, A. J. 1944. Notes on seed-borne fungi: II. Alternaria. Can. J. Res. 22:219-234.

Hong, S. G., and Pryor, B. M. 2004. Development of selective media for the isolation and enumeration of Alternaria species from soil and plant debris. Can. J. Microbiol. 50:461-486.

Joly, P. 1964. Le genre Alternaria: recherches physiologiques, biologiques et systématiques. Encyclopédie Mycologique 33:1-250.

Koike, S. T., Gladders, P., and Paulus, A. O. 2007. Vegetable Diseases: A Colour Handbook. Manson Publishing Ltd., London, United Kingdom.

Langenberg, W. J., Sutton, J. C., and Gillespie, T. J. 1977. Relation of weather variables and periodicities of airborne spores of Alternaria dauci. Phytopathology 67:879-883.

Lawrence, D. P., Park, M. S., and Pryor, B. M. 2012. Nimbya and Embellisia revisited, with nov. comb. for Alternaria celosiae and A. perpunctulata. Mycol. Prog. 11:799-815.

Neergaard, P. 1945. Danish Species of Alternaria and Stemphylium. Oxford University Press, London. 
Neergaard, P. 1957. Sixth and seventh annual reports relating to the control of seed pathology. Rev. Appl. Mycol. 47:515.

Neergaard, P. 1977. Seed Pathology. Halsted Press, New York.

Netzer, D., and Kenneth, R. G. 1969. Persistence and transmission of Alternaria dauci (Kuhn) Groves \& Skolko in the semi-arid conditions in Israel. Ann. Appl. Biol. 63:289-294.

Pryor, B. M., and Gilbertson, R. L. 2000. Molecular phylogenetic relationships amongst Alternaria species and related fungi based upon analysis of nuclear ITS and mt SSU rDNA sequences. Mycol. Res. 104:1312-1321.

Pryor, B. M., Strandberg, J. O., Davis, R. M., Nunez, J. J., and Gilbertson, R. L. 2002. Survival and persistence of Alternaria dauci in carrot cropping systems. Plant Dis. 86:1115-1122.
Richardson, M. J. 1990. An Annotated List of Seed-Borne Diseases, 4th Ed. Int. Seed Testing Assoc., Zurich, Switzerland.

Rogers, P. M., and Stevenson, W. R. 2010. Aggressiveness and fungicide sensitivity of Alternaria dauci from cultivated carrot. Plant Dis. 94:405-412. Simmons, E. G. 2007. Alternaria: An Identification Manual. CBS Fungal Diversity Centre, Utrecht, The Netherlands.

Soteros, J. J. 1979. Pathogenicity and control of Alternaria radicina and A. dauci in carrots. N. Z. J. Agric. Res. 22:191-196.

Strandberg, J. O. 1992. Alternaria species that attack vegetable crops: Biology and options for disease management. Pages 175-208. Alternaria Biology, Plant Diseases, and Metabolites. J. Chelkowski, and A. Visconti, eds. Elsevier Science Publ., Amsterdam, The Netherlands. 